\title{
Device Sensing Issue
}

National Cancer Institute

\section{Source}

National Cancer Institute. Device Sensing Issue. NCI Thesaurus. Code C63238.

Problem associated with the device feature that are designed to respond to a physical stimulus (temperature, illumination, motion, cardiac rhythms) and that do not transmit a resulting signal for interpretation or measurement. 